\title{
Why Beliefs Matter: Reflections on the Nature of Science
}

\section{Reviewed by Gerald B. Folland}

\author{
Why Beliefs Matter: Reflections on the Nature of \\ Science \\ E. Brian Davies \\ Oxford University Press, 2010 \\ US\$45.00, 256 pages \\ ISBN 978-0-19-958620-2
}

Brian Davies is a distinguished mathematician with a long list of publications in operator theory and related areas, but in recent years he has increasingly devoted his attention to the philosophy of mathematics and science. The book under review, according to the preface, began as a response to the reductionist view of the world espoused by some physicists, but it encompasses a good deal more than that.

It begins with a cogent account of the development of the scientific worldview from Copernicus to Newton, along with the more recent commentaries of people such as Karl Popper and Paul Feyerabend. There follows a chapter on the interactions between human intelligence, human culture, and the scientific understanding of the world. Its main point is a defense of the pluralist, or antireductionist, position that we obtain the fullest understanding of the phenomena around us by being flexible in adopting multiple points of view. The third chapter, on the nature of mathematics, is primarily a critique of Platonism in mathematics; I shall say more about it below. Chapter four, cryptically titled "Sense and nonsense", begins with a good summary of the Standard Model of elementary particle physics but then moves on to some speculative

Gerald B. Folland is professor of mathematics at the University of Washington. His email address is fol1 and@ math. washington. edu.

DOI: http://dx.doi.org/10.1090/noti 819

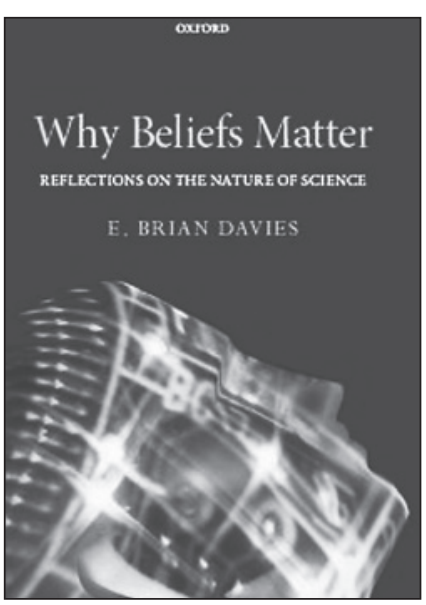

areas on the border between physics and science fiction: multiverses, wormholes, and simulated universes. The final chapter is on science and religion, but it includes some material on religious issues (primarily Christian and more specifically Anglican) that have little to do with science.

As the preceding thumbnail description suggests, in this book one will find intelligent and readable discussions of many scientific, mathematical, and cultural issues; there is intellectual pleasure to be found in many places here. On the larger scale, though, one may find that Davies's meandering line of thought leads to a certain lack of focus. Readers should not expect to have arrived at any profound philosophical conclusions at the end or indeed to have received any striking new answer to the issue posed in the title.

Davies buttresses his discussion of various issues with numerous quotes from the people whose ideas he considers, but he sometimes interprets these quotes in a more doggedly literal way than they were intended to bear. Let me cite one notable example. Davies has serious problems with the peculiarities of quantum mechanics; on p. 35 he calls it "a subject so difficult that even the experts do not claim to understand it at an intuitive level," and similar assertions are found in many other places in the book. In support of this position he quotes 
Richard Feynman: "It is safe to say that nobody understands quantum mechanics." This quote is offered in complete seriousness, but it seems obvious to me that Feynman had a twinkle in his eye when he came out with that bit of false modesty. What he meant-what is undeniably trueis that nobody can explain quantum mechanics in a way that is consistent with our everyday intuitions about the behavior of macroscopic objects. But that just means that, if one wants to understand the submicroscopic world, one has to retrain and refine one's intuition until it feels at home with the way things really work. I don't think this is much different from the process by which mathematicians train their minds to think about geometric phenomena that don't fit into our three-dimensional world: nobody can really see the locus of the equation $z^{6}+w^{6}=1$ in complex 2-space, but that doesn't mean that nobody can understand algebraic geometry. In another essay [1, p. 10] Feynman returned to this point in a way that is more indicative of his true feelings: "Please don't turn yourself off because you can't believe Nature is so strange. Just hear me out, and I hope you will be as delighted as I am when we are through."

For that matter, one doesn't have to go to quantum mechanics to find counterintuitive phenomena. A spinning gyroscope-a toy top, say-will remain balanced on the tip of its axis as long as it remains spinning. I understand why this works in the sense that I have faith in the law of conservation of angular momentum and know how to calculate its consequences. But that doesn't stop my untutored intuition from thinking that the damn thing ought to tip over.

Davies's critique of Platonism is based on what one might call strong Platonism: that mathematical objects have an objective existence that is independent of the people who study them, in an ideal realm that is outside of space and time. There are mathematicians who would agree wholeheartedly with this proposition; Alain Connes is one of them, according to some statements of his quoted by Davies, and so was G. H. Hardy [3, §22]. But it is quite possible to speak of mathematical objects in a Platonic way, as a convenient and useful method of expressing one's thoughts, without making a serious ontological commitment to the Platonic world. (In the same way, a physicist who describes an ultimate theory of elementary particles as "knowing the mind of God" is not necessarily presupposing the existence of God.) I talk about the real number system as a concrete entity that I know well, but if asked whether I really believe in its existence as a specific object in some ideal universe, I back off. I wish I could answer in the affirmative, but the utter failure of generations of set theorists to shed significant light on the continuum hypothesis saps my confidence to do so. I would rather echo Laplace's response when someone asked why he never mentioned God in his treatise on celestial mechanics: I have no need of that hypothesis.

Among the alternatives to Platonism, Davies pays considerable attention to constructivism, as it has played a substantial role in shaping his own thought. On the other hand, he gives short shrift to formalism. He presents a quote from Edward Nelson summarizing Nelson's formalistic views, expresses perplexity at Nelson's statement that "the theorems are not about anything," and then quickly moves on to other matters. I think this is unfortunate. Formalism deserves to be taken more seriously because, as I have pointed out elsewhere [2], it is the attitude of most scientists who use mathematics in their work. (I say "attitude" rather than "philosophy" because most appliers of mathematics are even less inclined than mathematicians to philosophize about the mathematics they use.)

Nelson's statement requires a little exegesis. What he is really saying (and I have heard him say precisely this) is that mathematics is all syntax, no semantics; in other words, (pure) mathematical statements are not about any particular thing. Hilbert expressed this point with his dictum that the theorems of Euclidean geometry should remain valid if one replaces points, lines, and planes with tables, chairs, and beer mugs. In a more sober vein, in calculus one can replace $x, f(x)$, and $f^{\prime}(x)$ by horizontal coordinate, vertical coordinate, and slope; or by time, position, and velocity; or by wave number, frequency, and group velocity; or by price, profit, and marginal profit; or... well, you get the idea. Appliers of mathematics are perfectly happy with the idea that mathematics is all syntax because they can supply the semantics from their own disciplines. On the other hand, I think that a large part of the appeal of Platonism for mathematicians is that thinking about pure syntax is difficult, and it becomes easier if one has something for the syntax to hang onto: hence our insistence on describing mathematical objects as specific sets and our tendency to speak of these sets as concrete objects. In other words, Platonism is of service more as a psychological tool than as a philosophical position.

In fact, I think the whole question of whether mathematics is a matter of discovery or invention -that is, of exploring a Platonic realm or creating new concepts with the human mind-is more interesting as a psychological question, a question about the human activity of doing mathematics, than as a philosophical one. It is this aspect of the matter that Barry Mazur primarily addresses in his book [4] and his essay [5], which are both highly recommended reading. One could hardly put it better than this:

On the days when the world of mathematics seems unpermissive, with its gem-hard exigencies, we all become 
fervid Platonists (mathematical objects are "out there", waiting to be discovered-or not) and mathematics is all discovery. And on days when we see someone who, Viète-like, seemingly by willpower alone, extends the range of our mathematical intuition, the freeness and open permissiveness of mathematical invention dazzle us, and mathematics is all invention. [4, p. 70]

But this is a statement about how we mathematicians think about what we do rather than about the ultimate nature of mathematical reality, whatever that might mean.

In any case, when someone has put a new mathematical concept into the realm of discourse, it is "out there" for the rest of us to explore (if you like) or add our own inventions to (if you prefer). With this realization, one can enjoy the interplay between discovery and invention without committing oneself to an exclusive belief in one or the other and leave the question of whether groups and topological spaces were already "out there" before Galois and Hausdorff to the metaphysicians. I suppose that Davies would say that I am advocating pluralism, but the need to label all one's thoughts in terms of various "isms" is a disease of philosophers. The unexamined life may not be worth living, but the unlabeled one enjoys the gift of freedom.

\section{References}

[1] R. P. Feynman, QED: The Strange Theory of Light and Matter, Princeton University Press, Princeton, NJ, 1985.

[2] G. B. Folland, Speaking with the natives: Reflections on mathematical communication, Notices Amer. Math. Soc. 57 (2010), 1121-1124.

[3] G. H. Hardy, A Mathematician's Apology, Cambridge University Press, Cambridge, U.K., 1940.

[4] B. Mazur, Imagining Numbers, Farrar, Strauss, and Giroux, New York, NY, 2003.

[5] B. Mazur, Mathematical Platonism and its opposites, European Math. Soc. Newsletter, June 2008, 19-21.

\section{New Orleans, LA, Joint Mathematics Meetings Photo Key}
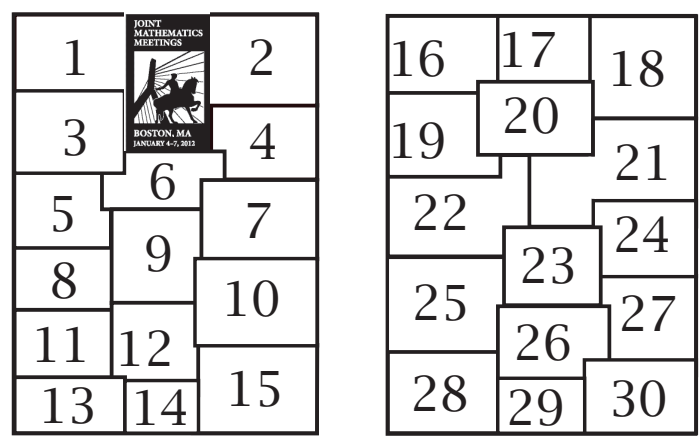

1. View of Boston from Hynes Convention Center.

2. AMS Employment Center.

3. AMS Booth in the Exhibits Hall.

4. Ivo Babuška, winner of the Steele Prize for Lifetime Achievement.

5. Fan Wei, winner of the AWM Alice T. Schafer Prize.

6. Email Center.

7. Ribbon cutting ceremony to open JMM Exhibits.

8. Prize Ceremony reception.

9. AMS Booth in the Exhibits Hall.

10. Mathematical Art Exhibit.

11. MAA Booth in the Exhibits Hall.

12. AMS Colloquium Lecturer Edward Frenkel.

13. Who Wants to Be a Mathematician contestants.

14. In the Networking Center.

15. Math games.

16. Networking Center.

17. William McCallum, winner of the AMS Award for Distinguished Public Service.

18. Prize Ceremony reception.

19. William Thurston, winner of the AMS Steele Prize for Seminal Contribution to Research.

20. Mathematical Art Exhibit.

21. In the Exhibits Hall.

22. Networking Center

23. Shayam Narayanan (left), winner of 2012 Who Want to Be a Mathematician national contest.

24. Who Want to Be a Mathematician host Mike Breen and contestants.

25. Meeting and greeting.

26. Bonnie Gold, winner of the AWM Louise Hay Award.

27. John Pardon, winner of the AMS-MAA-SIAM Morgan Prize.

28. Joseph Dauben receiving the AMS Whiteman Prize from AMS President Eric Friedlander.

29. Dana MacKenzie, winner of the JPBM Communications Award.

30. Exhibits Hall. 